thirty miles of valleys and mountain land to reach it, and, once there, you are surrounded by mountains on every side, many of which were covered with snow when I was there, early in November.

Rome is a winter residence for healthy tourists, not for invalids. The malaria reigns there, more or less, all the year. Every winter it makes victims, even among the healthy. Moreover, invalids should scrupulously avoid churches, galleries, festivities, and parties: and what is Rome without these, the life of the Eternal City? merely a temptation and a snare. I may add, all that has been said about the dirt, defective drainage, and general unhealthiness of Genoa and Pisa, equally apply to Florence and Rome.

Thus, I had to continue my pilgrimage, and started from Civita Vecchia for Naples. I did not intend to remain there, but to go on to Salerno, the celebrated medical school of former days, which is near, and admirably situated on the map. Naples exhibits the concentration of all the unhygienic conditions previously alluded to. More than 500,000 dirty Southerners are living in an extremely confined space, in high houses, in damp sunless streets, in the midst of every imaginable abomination by which the eye and the smell can be offended. The drains all run into the tideless sea, or on to the shore. In the most fashionable part of the town, in front of the houses occupied by the nobility and by strangers, is a narrow public garden, the fashionable promenade, "the Chiaja," running for a mile along the shore. On this shore eight public drains empty themselves, not into the sea, but on to the sands, then to trickle down by slow degrees. The largest is opposite one of the chief hotels, and is usually so offensive, that those who are alive to these questions always feel inclined to take a run in passing. On the land side of this garden is the main drive, or street, and on each side of the pavement, as in most other streets, there are large slits in the road every few feet, a foot long and about an inch broad, to allow the rainwater to escape into the drains, which thus freely communicate with the exterior. It is between these shore drains on the one side, and the drain-ventilated street on the other, that fashionable Naples daily promenades, and it is by the side of this choice region that our countrymen live, and, not unfrequently, die. The picturesqueness of Naples life, closely analyzed, is, in a great measure, that of filth, dirt, and rags. The picturesque fishermen pass their lives fishing at the mouth of these sewers. The picturesque lower orders eat, drink, and sleep, as it were, in public, windows and doors open, if they have any. They are clothed in rags, which they appear never to take off until they fall from them, and they are infested with vermin, which they scratch off each other at every streetcorner. The town is surrounded by pestilential marshes, and is built on a tufa rock, or kind of pumice stone, so porous that it lets the rain soak in twenty feet, to give it out later by degrees. Thus moss grows in winter wherever the sun does not reach.

A few days after my arrival in November, the autumn rains commenced with a warm oppressive sirocco, or south-east wind. The torrents of rain that fell in the first twelve hours washed the streets and drains of their accumulated abominations into the sea. The wind and waves, on the other hand, drove them back again and again on the shore, whilst the wind, rushing up the open drains, escaped through the rain openings in the streets, and through the open closets in the houses. The smell throughout the entire lower part of the city was awful, and a considerable portion of the population was at once affected with abdominal pains, diarrhoea, and even dysentery. I was one of the first victims, and after nearly three weeks' illness, was only too glad to embark on a Genoa steamer, and to return to pure, healthy Mentone, where I spent the rest of the winter.

To conclude, however, about Naples and its bay. They are most fascinating to the mere healthy tourist, hallowed by associations and beauties of the most varied character. But to the invalid, Naples should be absolutely forbidden. The defective sanitary arrangements are not the only drawbacks. When the wind is in the north-east, the Apennines in that direction are so low that it passes over them, and they become covered with snow, and the cold is intense. When it veers to the south-east, the sirocco, on the contrary, the heat becomes intense, and the air, being loaded with moisture from the sea, is very oppressive. These extremes, following each other rapidly, are very trying and unhealthy. The north-west, or mistral, also, frequently blows into the bay with great violence, and is a trying, dan. gerous wind to invalids throughout the Mediterranean.

Grosvenof-street,14ay, 1861

(To be coneluded.)

\section{REPORT OF FOUR CASES}

oF

\section{TEMPORARY PARALYSIS OF THE CILIARY MUSCLE OF THE EYE.} PERFECT RECOVERY.

By GEORGE LAWSON, EsQ, F.R.C.S., SURGEON TO THE GREAT NORTHERN HOSPITAL, CLINTCAI ASISTANT, BOYAI LONDON OPHTHALMIC HOSPITAL, MOORFIELDE,

THe following cases illustrate a partial or entire paralysis of the ciliary muscle of the eye. I call this affection paralysis. of the ciliary muscle; for the accommodation of the eye being performed through its agency, any sudden loss of the power of adjusting the eye for near objects occurring in an eye which has always had normal vision must depend on some impairment in the function of this muscle, which may be either partially or entirely paralysed. From the few cases which have fallen under my observation, this ailment appears generally to come on either during a severe illness, or else, as is more frequently the case, it is first discovered by the patient during the period of convalescence, when, on attempting to read, he finds that the lines appear misty, and that he is unable to dis. tinguish the words.

The symptoms are those of a total or almost complete loss of the power of accommodation in the eye. The patient is unable to focus his eye for near objects, and surrounding bodies appear indistinct. In one of the cases I have related, the patient could see well objects at a certain distance, could read at twenty-six feet the markings on the clock - in fact, she was able to appreciate those objects which were far enough off to allow the parallel rays proceeding from them to form a focus on her retina without any effort of adjustment of her own; while at the same time she could not clearly distinguish near objects or read large ordinary type. She could only make out with diff. culty the letters of words in Canon type, the size known as No. 18 in the test type used at the Moorfields Ophthalmic Hospital. In each case, with a slightly convex glass, the patient was able to read clearly moderate-sized print at its focal distance. The lens rendered the object clear without magnifying it. The prognosis may, I think, be favourable ; for in eaeh. of the four following cases a speedy recovery to good vision followed the treatment, which consisted in resting the eyes, (not allowing them to attempt reading, the free use of iron, quinine, and purgatives, and cold sponging and splashing the body.

It is difficult to assign a true cause for this affection, or to suggest what pathological state produces it. This palsy of the ciliary muscle is analogous to the partial or entire paralysis. which frequently attacks certain muscles or sets of muscles, especially those of the lower extremity, thus allowing a preponderance of action to their opponents, and producing some of the forms of the non-congenital varus and valgus. Why certain muscles should after a long or a depressing illness become paralysed, while others in the same limb remain unaffeeted, it is difficult, if not impossible, to say ; but the fact is well known, although we cannot comprehend in what manner such aresult is effected.

CASE 1.-June, 1855.-A. B-_-, aged twenty-six, an officer who had suffered severely from fever and dysentery in the Crimea, consequent on the necessary exposure and bad living during the winter months of that campaign. At the time I now allude to, he was in a very feeble state, the resilt of his illness; his legs were cedematous, and there was some fluid in his belly; he had great muscular debility, and was incapable of walking even a few yards. One day he noticed accidentally that on attempting to read, the lines were cloudy and the letters indistinct, and that he was unable to continue reading for more than a few minutes. Day by day the symptoms increased, until at about the expiration of a week he could not make out a word of any ordinarily printed book. There were, however, objects at a certain distance which he was able to see, but at what distance I cannot say. At his own suggestion, he was permitted to try a pair of spectacles, with moderately convex glasses, and he then found that at their focal distance he could read well. Deriving much benefit from the glasses, he wore them for about a fortnight or three weeks, when his sight began to improve, and was in a short. 
time as good as ever. He has never since been troubled with any similar affection.

Case 2.-Feb. 4th, 1860.-Fanny $\mathrm{P}$ - - aged nine. Has always had good health, with the exception of scarlet fever five years ago. She has continued well until one month since, when she had what her mother calls diphtheria, her throat being very sore and her breathing very difficult. Before this attack her sight had been always good, and she had learnt to read and write well. She now complains of indistinctness of vision and an inability to read any of her books. She can read Double Pica print, known as No. 14 of the Moorfields test type; but she is unable to distinguish smaller letters. With a twentyinch focus convex glass she can read with facility, and all surrounding objects appear much clearer to her. She was treated with iron, purgatives, and cold sponging, and the report state, on March 8 th-She can now read the smallest Brilliant, or No. 1 type.

CASE 3.-Sept. 4th, 1860. - Sarah H_, aged twelve, six weeks ago had an acute attack of urticaria, which lasted a week, during which time she was very ill. Her appetite was very bad, and she became-much exhausted. A fortnight or three weeks ago she complained that near objects appeared muddy, but that distant ones were clear. She had previously had good sight, and had learnt to read and write. She is now unable to read or to follow her school duties. With either eye she can only make out the letters of Canon type, or No. 18 of the Moorfields test-type; but she is able to see the clock and tell the time at a distance of twenty-six feet. Her sight is much improved by a 28 -inch focus convex glass; and with it she is enabled to read No. 10, or Pica type. She was ordered a powder of calomel and scammony at bed-time, steel medi cine twice a day, to sponge the body daily with cold water, and rest the eye. She gradually improved, and, on Oct. 2 nd she could read Brilliant print, or No. 1 , with either eye.

CAsE 4. - Sept. 11th, 1860._-Thomas F__, aged ten, a fair, delicate boy, who has suffered from measles, whooping-cough, and small-pox, from all of which he has made a fair recovery; but his mother says he has never regained his former healthy appearance, and that for the last year, although he has had no decided illness, yet for several months previous to his eyes becoming affected he had been much troubled with frequent attacks of sickness and headache. Up to within the last three months he has always had good sight, and has learnt to read. He was accustomed to much reading; but about three month ago he says that he found one day while reading that the print became dizzy, and that he was unable to discern the words. His sight became rapidly worse, and he was shortly unable to read at all. With either eye he can only make out the words of four-line condensed type, or No. 19 of the Moorfields test type; but he can see the clock and tell the time at the distance of twenty-six feet. With a 16-inch focus convex glass he can read No. 8, or Small Pica type. This patient was treated in the same manner as the others-with preparations of iron, pur gatives, cold sponging, and complete rest for the eye.

Sept. $30 \mathrm{th}, 1860$. - He can now read No. 1, or Brilliant type, with the greatest ease.

Dec. 1 st.-He is now at work, and his mother states his sight continues very good.

Park-street, Grosvenor-square, April, 1861.

Wrdows of Naval Surgeons. - The Royal Naval Supplementary Fund was established in 1817, and by an order in council then issued every member of the medical profession in the Royal Navy was required to pay $1 s$. per week towards the funds, and, if beneficial members, to subscribe according to a scale laid down, and which entitled the widows of such members to receive an annuity of $£ 40$. About thirty years after the formation of the Fund it was found that this amount could not be paid, and the widows then agreed to receive two thirds, or £26 13s. 4d., and an Act was passed making such payment legal. Recently an attempt has been made to obtain a dissolution of the Society; but, on the other hand, the widows have forwarded a numerously signed requisition to the Admiralty, praying that their vested rights may be preserved, and the payment increased to $£ 40$ per annum, as originally promised. An answer to the following effect has been received from Lord Clarence Paget:- "That until the First Lord and the Secretary of the Admiralty are of opinion that the state of the Fund will allow of an increase in the amount of pension, the memorialists are not entitled to receive more than at pre. sent."

\section{Ithrtot}

OF THE PRACTICE OF

\section{MEDICINE AND SURGERY IN THE}

\section{HOSPITALS OF LONDON.}

Nulla est alia pro certo noscendi via, nisi quam plurimas et morborum et dissectionum historias, tam aliorum proprias, collectas habere et inter se comparare.-Morgagnr. De Sed, et Caus. Morb., lib. 14. Procemium.

\section{KING'S COLLEGE HOSPITAL.}

LARGE COLLOID TUMOUR ON THE LEFT SIDE OF THE BACK, SIMULATING A FATTY GROWTH; SUCCESSFUL REMOVAL.

(Under the care of Mr. FkRGusson.)

THE colloid form of cancer has attracted considerable attention from its peculiar nature and apparent rarity. Although first described by Laennee under the name- of tissu or matiere colloide, much diversity of opinion prevailed amongst pathologists in regard to its essential characters, until the question was set at rest by Dr. Walshe, who assigned to colloid the rank of a species in juxta-position with scirrhus and encephaloid.

Into a description of this form of cancer we do not purpose to enter, but we may observe that the appearance which it presents on section is quite unmistakable. It usually occurs as a distinct tumour, as in two of the examples we record today. It is known, however, to infiltrate any of the tissues it may attack-e. g., the mucous membrane; tw: excellent examples of which were exhibited by Dr. Andrew Clark at the last meeting of the Medical Society of London. The seat of the disease in each of these cases was the sigmoid flexure of the colon.

The dimensions of colloid growths are sometimes very considerable. We have already recorded an instance of large tumour of this kind in the thigh of a female, which was re. moved by Mr. Marshall at University College Hospital (Tre LANCET, vol. i. 1857, p. 552); but it was exceeded in size by that extirpated by Mr. Fergusson, which is perhaps the largest. specimen in any London museum.

The peritoneum is not an uncommon seat of colloid, several interesting examples of which have been brought at different times before the Pathological Society, and are preserved in some of the museums. Colloid does not invade particular organs to the same extent as do the other species of cancer. It was believed to be almost unknown in the liver, until Dr. Wilks brought to light the unique specimen in the Guy's Museum recently shown to the Pathological Society. On examining the specimen, it would seem as if the colloid had first attacked the peritoneum, and had then invaded the liver. Unfortunately, no early history of the case is known. The form of cancer in question is sometimes associated with other species, especially scirrhus, and the fluid contents vary in colour, consistence, and composition. It might be supposed that gelatin would naturally enter into the formation of the jelly-like matter; but Müller was unable to find a trace of it. The chemistry of colloid should be considered in doubtful cases. There are many ovarian tumours to which the same term has been applied, but with questionable propriety.

In the following case, the notes of which were furnished by Mr. C. S. Matthews, house-surgeon to the hospital, it is highly probable that the tumour was originally fatty and had become transformed into colloid. The appearance it presented on section after removal strongly tended to confirm this opinion. In external characters, and in the facility with which it was removed by the knife, it greatly resembled an ordinary fatty tumour.

G. G-, aged fifty-two, a coachman, is married, and lives some twenty miles from town. About six years ago he first perceived a lump on his back, which, however, caused him no pain nor inconvenience of any kind. This has been growing gradually ever since, but much more rapidly lately, and is now only inconvenient from its great size and weight. He was admitted into the hospital on the $19 \mathrm{th}$ ult.

On admission there was a large pedunculated tumour situated 